\title{
The effect of surface treatment on the brain delivery of curcumin nanosuspension: in vitro and in vivo studies
}

\author{
Maryam Dibaei' \\ Mohammad-Reza Rouini ${ }^{1}$ \\ Behjat Sheikholeslami' \\ Mahdi Gholami ${ }^{2,3}$ \\ Rassoul Dinarvand ${ }^{4,5}$
}

'Biopharmaceutics and Pharmacokinetic Division, Department of Pharmaceutics, Faculty of Pharmacy, Tehran University of Medical Sciences, Tehran, Iran;

${ }^{2}$ Experimental Medicine Research Center, Faculty of Pharmacy, Tehran University of Medical Sciences, Tehran, Iran;

${ }^{3}$ Department of Pharmacology and Toxicology, Faculty of Pharmacy, Tehran University of Medical Sciences, Tehran, Iran; ${ }^{4}$ Nanotechnology Research Centre, Faculty of Pharmacy, Tehran University of Medical Sciences, Tehran, Iran;

${ }^{5}$ Department of Pharmaceutics, Faculty of Pharmacy, Tehran University of Medical Sciences, Tehran, Iran
This article was published in the following Dove Press journal: International Journal of Nanomedicine

Background: Curcumin, a bioactive component with multiple characteristics, has been shown to have many therapeutic effects. However, there are several limitations regarding the use of curcumin such as instability, low solubility, poor bioavailability, and rapid elimination. Different approaches have been used to solve these problems.

Materials and methods: In this study, surface-modified nanosuspension (NS) is investigated as a novel brain delivery system. Two different methods were used for the preparation of nanosuspensions with two different stabilizers. The surface of the nanosuspensions was coated with D- $\alpha$-tocopheryl polyethylene glycol 1,000 succinate (TPGS) and Tween 80 using physical adsorption. Curcumin NSs were prepared using two different top-down techniques by high-pressure homogenizer and probe sonicator. A validated sensitive and selective highperformance liquid chromatography method using fluorescence detection was used for the determination and quantification of curcumin. Pharmacokinetics and biodistribution of curcumin NSs and solutions after intravenous administration in rats were studied.

Results: Higher levels of curcumin in the brain were detected when Tween 80-coated NS was used compared with the curcumin solution and TPGS coated NS (TPGS-NS) $(P$-value $<0.05)$. Absorption of ApoE and/or B by Tween 80-coated nanoparticles (NPs) from the blood were caused transferring of these NPs into the brain using receptor-mediated endocytosis. Distribution of TPGS-NS in the brain compared with the curcumin solution was higher $(P$-value $<0.05)$. Higher levels of curcumin concentration in the liver, spleen, and lung were also observed with TPGS-NS.

Conclusion: The results of this study indicate that the surface-coating of NSs by Tween 80 may be used to improve the biodistribution of curcumin in the brain.

Keywords: curcumin, nanosuspensions, pharmacokinetics, biodistribution, Tween 80, TPGS

\section{Introduction}

Curcumin is an active substance of Curcuma longa with extensive biological and pharmacological applications. ${ }^{1}$ A high partition coefficient (log P) of between 2.3 and 2.6 has been calculated for curcumin. It is a hydrophobic agent despite the polarity feature of the functional groups and the central dicarbonyl moiety; thus, it has poor solubility in aqueous but good in organic solvents. ${ }^{2}$ Previous studies have shown a wide spectrum of activities for curcumin (including anti-tumor, ${ }^{3-5}$ antiinflammation, ${ }^{2}$ anti-protozoa, antimicrobial, ${ }^{4}$ anti-osteoporotic, ${ }^{6}$ anti-oxidant activities, and wound healing effects ${ }^{7}$ ) with the ability to trigger varied cell apoptosis. ${ }^{4,8}$ Some researchers have reported that the progression of Alzheimer's disease can be 
slowed by consuming curcumin because it lowers the amyloid $\beta$ level $;{ }^{9,10}$ other studies have shown that using curcumin can hinder seizure activity induced by kainic acid, ${ }^{11}$ prevent brain tumor formation, ${ }^{12}$ and play an active role in cerebral ischemia. ${ }^{13}$ Other positive aspects of this substance include safety, tolerability, and costeffectiveness. ${ }^{14}$ Nevertheless, curcumin consumption faces poor bioavailability due to various shortcomings, including poor water solubility, low absorption, rapid metabolism, and excretion., ${ }^{14}$

One of the perennial challenges of pharmaceutical research is dealing with poorly water-soluble molecules, which account for $40 \%$ or more of novel chemical mediations. ${ }^{15}$ In this regard, there are some new promising approaches, including nano-sized drug delivery in the forms of liposomes, ${ }^{16}$ polymeric micelles, ${ }^{17}$ and nanoemulsions; ${ }^{18}$ which is useful for various reasons, such as high bioavailability, less patient variability, prolonged circulation time, and targeted delivery. ${ }^{1,14,19}$ The concerns with these strategies include poor drug loading capacity, low physical stability, and complications related to solubilizing or encapsulating excipients. Among the nano-sized drug delivery strategies, nanosuspension (NS) (also known as nanocrystals) is a method that has been used for poorly water-soluble medications. ${ }^{19}$

The NSs have sub-micron unique liquid colloidal dispersions of pure drug as nanosized particles, which are stabilized by proper polymers and/or surfactants. ${ }^{20-22}$ The bottom-up and the top-down approaches can be employed to synthesize these nano-crystalline entities. ${ }^{23}$ Side effects of these nanomaterials caused by excipients attenuate as less excipients used without any organic solvent. The fate of NSs in the body is influenced by some properties, such as size and size distribution, dissolution rate, saturation solubility, and surface hydrophilicity/hydrophobicity. ${ }^{24}$ These nanoparticles (NPs) can improve drug bioavailability due to their large specific surface areas, which enhance drug saturation solubility and dissolution rate. ${ }^{25}$ In the other hand, their thermodynamically unstable formulation, with a tendency toward agglomeration or crystal growth, requires the use of common stabilizers with steric or electrostatic impacts, such as polyvinylpyrrolidone (PVP), hydroxypropyl methylcellulose, D- $\alpha$-tocopheryl polyethylene glycol 1,000 succinate (TPGS), and Tweens. ${ }^{19}$

NSs reportedly allow for the targeting of various sites, such as the mononuclear phagocytic system (MPS) and blood-brain barrier (BBB). ${ }^{26-28}$ Neurotherapeutic drugs are applied to treat the brain or central nervous system
(CNS) disorders. ${ }^{29}$ The penetration of many drugs into the brain can be blocked by the $\mathrm{BBB} ;{ }^{26-28}$ the structure of the BBB consists of brain capillary endothelial cells with tight junctions that expresses efflux transport proteins, preventing the transportation of substances into the brain and maintaining CNS homeostasis. ${ }^{30,31}$ NPs are recently developed drug delivery systems for the brain. ${ }^{32}$

One of the significant factors affecting the fate of NSs is particle size. Solution like behavior because of very fast dissolution expected with a small particle size $(<100 \mathrm{~nm})$ and higher cellular uptake due to uptake by the reticuloendothelial system (RES) observed with larger crystals after intravenous administration. ${ }^{33}$ If their dissolution in plasma is not rapid so the plasma protein would be adsorbed on the surface of NSs. ${ }^{27}$ For a long time, the surfactant-coated NPs supported drug delivery to the brain. The controlled surface modification could improve the effectiveness of the NSs during in vivo conditions. Therefore, the surface composition of the NSs is a key factor for organ distribution. ${ }^{34-36}$

A substance facilitating drug delivery into the brain is polyethylene glycol sorbitan monooleate (Tween 80), which is the gold standard coating surfactant and is useful for various NPs, such as poly (alkyl cyanoacrylate), ${ }^{12,27,37}$ poly (lactide-co-glycolide), ${ }^{38}$ and solid lipid NPs. ${ }^{39}$ This occurs after serum apolipoprotein $\mathrm{E}$ adsorption on Tween 80-coated NP surfaces, which can lead to act like lowdensity lipoprotein (LDL) and subsequent interactions with LDL receptors on the BBB; this results in a highly cellular uptake through a receptor-mediated transcytosis mechanism. ${ }^{29}$ Another tool contributing to the study of a stabilizer's effectiveness when preparing the NS in target delivery is TPGS, a water-miscible form of vitamin $\mathrm{E}$ that contains a hydrophobic vitamin $\mathrm{E}$ part and a hydrophilic PEG chain. This special amphiphilic structure makes it an excellent candidate for drug delivery. It is a common and safe pharmaceutical adjuvant and surfactant that has been approved by the FDA. It also plays an important role in drug delivery systems as a solubilizer, stabilizer, and P-gp inhibitor for enhancing bioavailability and reversing multiple drug resistance (MDR) ${ }^{40,41}$ Some of the current applications include being a stabilizer for nanodrugs and being a stabilizer for many poorly water-soluble or permeable medications - especially for biopharmaceutics classification system class II and IV drugs. ${ }^{40}$

In addition to the importance of drug activity, the desired targeted delivery of a drug is also important to the same degree. Accordingly, the present study aimed to investigate the effects of curcumin as the model drug as well as 
Tween 80 and TPGS as the coating surfactants on the derived variations in biodistribution of NS drug delivery.

\section{Materials and methods Materials}

Curcumin was obtained from India (Sabinsa Corporation). The sample comprised a blend of three curcuminoids, curcu$\min (95 \%)$, demethoxycurcumin, and bisdemethoxycurcumin (the latter two consisting of the remaining 5\%). Tween 80 was received from Merck (Darmstadt, Germany). TPGS was from Sigma-Aldrich Co. (St Louis, MO, USA). The rest of the chemicals and solvents were of analytical reagent grade.

\section{Formulation of curcumin NSs with various stabilizers}

The TPGS-NS and Tween-NS were formulated by two methods differently, in which various process parameters were optimized to obtain the least possible size and distribution of particles. ${ }^{20,42}$ Tween 80 and TPGS were composed individually as a $1 \%$ aqueous solution. Using an Ultra Turrax T25 homogenizer equipped with an $18 \mathrm{G}$ rotor (IKA, model T25 ULTRA-TURRAX, Germany), the curcumin powder (1\%) was dispersed in each aqueous phase at 20,000 rpm in an ice bath for 5 mins.

The Tween 80 pre-mix was homogenized using an IKA $^{\circledR}$ high-pressure homogenizer (Werke GmbH \& Co., Germany) to make NS. The optimized parameters included homogenization pressure and homogenization cycles. Homogenization of the presuspension was performed at the pressures of 200 and 500 bar for 5 mins, followed by running 20 cycles at 900 bar in order to obtain the NS.

A probe sonicator (Cole Parmer, Germany) was applied to prepare TPGS-NS. The power, frequency, and exposure time were the critical parameters of probe sonication. Afterward, the TPGS-NS was well created using probe sonicator via $90 \%$ vibration amplitude in an ice bath during 15 mins to preserve a continuous temperature.

In order to remove both impurities and large particles, the formulated TPGS-NS and Tween-NS were centrifuged at 3,000 rpm for 3 mins.

Curcumin solution was made with dimethyl acetamide (15\%), PEG $400(45 \%)$, and 5\% isotonic dextrose solution $(40 \%)^{40}$

\section{Physical characterization of curcumin NSs Particle size and zeta potential measurements}

The measurements including mean particle size, poly dispersity index (PDI), and zeta potential of curcumin NSs were performed by a Malvern Zetasizer (Nano ZS3000; Malvern, UK) following proper dilution. The polystyrene latex cells were filled by NSs at $25^{\circ} \mathrm{C}$. Mean values \pm standard deviation were used after making three measurements per sample.

\section{X-ray powder diffractometry (XRD)}

XRD was used to find out the crystallographic structure of the nanoparticulate curcumin preparation. Using a Dmax-MSAL $12 \mathrm{~kW}$ high power powder diffractometer (Dmax-MSAL, Rigaku, Japan), the X-ray powder diffraction patterns of powdered curcumin, physical mixture of TPGS solution and curcumin, physical mixture of Tween 80 solution and curcumin, TPGS-NS, Tween-NS, and curcumin-NS with no stabilizers were determined. The operation of X-ray diffractometer was run at a scan rate of $4^{\circ} \mathrm{C} / \mathrm{min}$ for $2 \Theta$ between $5^{\circ} \mathrm{C}$ and $40^{\circ} \mathrm{C}$.

\section{Scanning electron microscopy (SEM)}

The characteristic morphology was examined by SEM (Philips XL 30, Philips, The Netherlands). Gold-coating was initially conducted on NPs in a DC-magnetron sputtering at an argon pressure of $6 \mathrm{kV}$ with $6 \mathrm{MA}$ current.

\section{Short-term stability study}

The curcumin-NSs were tightly sealed in glass containers to evaluate their stability by incubating at $4^{\circ} \mathrm{C}$ within 7 days (on days $0,3,5$, and 7 ). The mean particle size and PDI were taken as indicators of formulation stability.

\section{Dissolution evaluation}

Dissolution profiles of both NSs and pure curcumin powder were evaluated by apparatus II (at $75 \mathrm{rpm}$ ) at predetermined time intervals $(5,10,15,30,60,120$, and 180 mins). The NSs (equivalent of $5 \mathrm{mg}$ curcumin) were released into $900 \mathrm{~mL}$ dissolution medium (phosphate buffer saline [0.01 M, pH 7.4] containing $2 \%$ of sodium dodecyl sulfate). After mentioned intervals, $1 \mathrm{~mL}$ medium was withdrawn and then centrifugation (14,000 rpm for 15 mins), the supernatant was analyzed by HPLC.

\section{Chromatographic assay}

For chromatographic separation, a Krnauer HPLC system (Berlin, Germany) was employed equipped with a lowpressure gradient HPLC pump, a variable fluorescence detector, and an online degasser, all from Knauer (Berlin, Germany). A reversed phase $\mathrm{C}_{18}$ analytical column $(4.6 \times 250 \mathrm{~mm}$, particle size $5 \mu \mathrm{m})$ was used with mobile phase containing two components of acetonitrile: $1 \%$ citrate buffer adjusted to a $\mathrm{pH}$ value of $4(50: 50, \mathrm{v} / \mathrm{v})$ 
delivered in an isocratic mode. The flow rate was sustained at $1.2 \mathrm{~mL} / \mathrm{min}$. Optimized measurements for excitation and emission wavelength of eluate's fluorescence were obtained at 420 and $530 \mathrm{~nm}$, respectively. The recording and calculation of data was completed by Chrom Gate ${ }^{\circledR}$ chromatography software.

Curcumin stock solution $(1 \mathrm{mg} / \mathrm{mL})$ was prepared in acetone. The working standard solutions (diluted with water:anetonitrile 50:50) were diluted with blank plasma to prepare plasma samples for calibration at different concentrations. Extraction processes were according to those described for sample preparation ("Tissue distribution and sample preparation"). Recovery of experiments was conducted to validate curcumin extraction and quantification methods from rat plasma and organs. The within-day and between-day accuracy and precision determinations and the recovery study were fulfilled by three different QC samples with three replicates.

\section{Pharmacokinetics study}

The ethics committee of Tehran University of Medical Sciences approved the study protocol. The animal welfare care was considered based on the followed guidelines "Handbook of laboratory animal science, An overview of global legislation, regulations and policies on the use of animals for scientific research, testing, or education, and Animal rights according to Quran viewpoints". ${ }^{43-45}$ The pharmacokinetics were examined in male wistar rats $(250 \pm 20 \mathrm{~g})$, which were bred at central animal house of the university, to be used in this research. The rats were kept under standard (25 $\pm 2^{\circ} \mathrm{C}, 60-70 \%$ humidity) laboratory settings at $12 \mathrm{hrs}$ dark and light cycle.

The experimental rats $(n=18)$ were randomly grouped in triples and anesthetized generally by injection of a ketamine-xylazine mixture (ketamine $100 \mathrm{mg} / \mathrm{kg}$ and xylazine $10 \mathrm{mg} / \mathrm{kg}$ ) intraperitoneally (IP), followed by insertion of a polyethylenesilicone rubber catheter in their right jugular veins according to the standard surgical operation. $^{46}$ Curcumin solution, Tween-NS, and TPGSNS were administered as a $10 \mathrm{mg} / \mathrm{kg}$ of curcumin single bolus dose on the next day. The right jugular vein was catheterized to facilitate blood sampling. For pharmacokinetic analysis, blood samples $(400 \mu \mathrm{L})$ were taken at intervals of $0,0.25,0.5,0.75,1,2,3,4,5$, and $6 \mathrm{hrs}$ following administration and stored in collection tubes impregnated with lithium heparin. In order to isolate the plasma, the blood samples were centrifuged immediately at 5,000 $\mathrm{rpm}$ for $10 \mathrm{mins}$ and stored at $-70^{\circ} \mathrm{C}$ for further analysis.

\section{Tissue distribution and sample preparation}

The wistar male rats weighing $100 \pm 20 \mathrm{~g}$ were investigated for organ biodistribution studies designed as three randomly assigned groups of rats with six animals at each time points. General anesthesia was induced by the IP injection similar to the anesthetic cocktail described above ("Pharmacokinetics study"). Three formulations, TPGS-NS, Tween-NS, and curcumin solution were injected at a dose of $10 \mathrm{mg} / \mathrm{kg}$ and blood samples were withdrawn at $0.25,0.5,0.75,1,2$, and 3 hrs after injection. Both injections and blood sampling were done via cardiac puncture.

The rats were then promptly decapitated and the organs (liver, heart, spleen, lung, kidney, and brain) were removed and preserved frozen until the time of drug analysis.

After weighing of organs and addition of saline $(1: 2 \mathrm{w} /$ v), the organs were homogenized by a high-speed homogenizer (IKA, model T25 ULTRA-TURRAX, Germany) and the supernatant was obtained for analysis.

Each biological sample $(100 \mu \mathrm{L})$ was mixed with acetonitrile $(200 \mu \mathrm{L})$, shaken for $10 \mathrm{mins}$, and centrifuged at $12,000 \mathrm{rpm}$ for $10 \mathrm{mins}$. The supernatant $(100 \mu \mathrm{L})$ was collected and analyzed by a validated HPLC method.

\section{Pharmacokinetic application and statistics} Using the plasma curcumin concentration-time data, the pharmacokinetic parameters of formulations were determined by non-compartmental methods through PK Solver, ${ }^{47}$ the results are reported as mean \pm standard deviation. To evaluate the impact of the formulation on the in vivo results $(n=6)$, data were analyzed by one-way ANOVA and Holm-Sidak tests at a significance level of $P$-value $<0.05$ using SigmaPlot software (Version 11, USA).

\section{Results and discussion NS preparation}

Particle size and distribution are key parameters in NS preparation, as the stabilization of pure drug particles can theoretically occur using a stabilizer. ${ }^{48}$ For achieving the minimum size, different methods were tested (not shown). Each surfactant has specific critical micelle concentrations (CMC) and hydrophile-lipophile balance. So, the size and stability of NSs may be influenced by the used stabilizers. ${ }^{21}$ 
The influence of five stabilizers on the particle size of curcumin NSs prepared by HPH was evaluated by Rachmawati and coworkers. ${ }^{49}$ When TPGS was used as a stabilizer, the smallest size was obtained. The size decreased in order to: $\mathrm{Na}-\mathrm{CMC}>\mathrm{PVA}>\mathrm{PVP}>\mathrm{SDS}>\mathrm{TPGS}$. Finally, two separate techniques were applied to synthesize

$\begin{array}{rllll} & & \text { Diam.(nm) } & \text { \% Intensity } & \text { Width (nm) } \\ \text { Z-Average (d.nm): } 197 & \text { Peak 1: } & 211 & 100.0 & 46.1 \\ \text { Pdl: } 0.199 & \text { Peak 2: } & 0.00 & 0.0 & 0.00 \\ \text { Intercept: } 0.798 & \text { Peak 3: } & 0.00 & 0.0 & 0.00\end{array}$

Size distribution by intensity

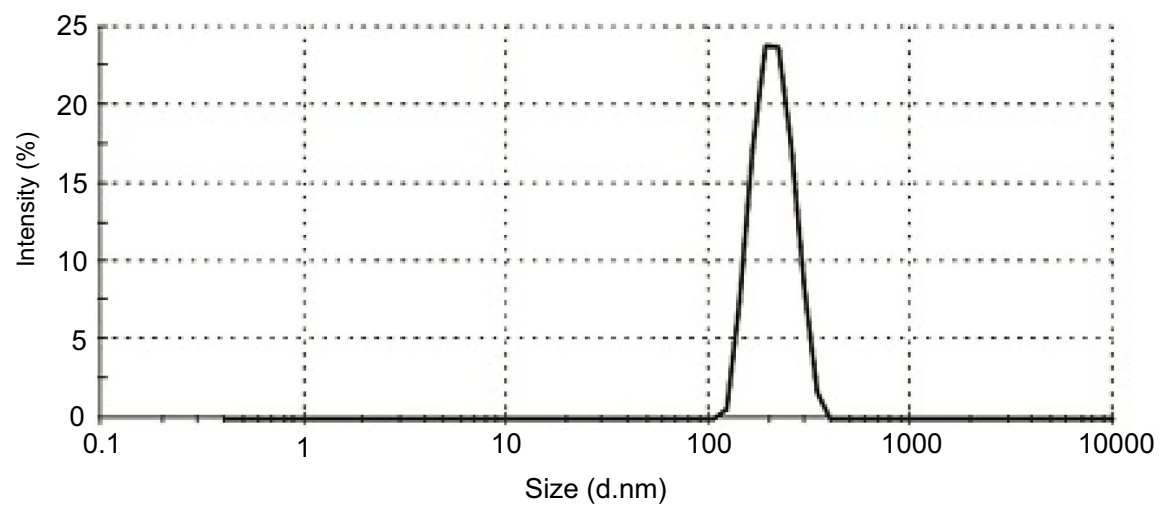

$\begin{array}{rllll} & & \text { Diam.(nm) } & \% \text { Intensity } & \text { Width (nm) } \\ \text { Z-Average (d.nm): } 184 & \text { Peak 1: } & 208 & 100.0 & 45.2 \\ \text { Pdl: } 0.196 & \text { Peak 2: } & 0.00 & 0.0 & 0.00 \\ \text { Intercept: } 0.822 & \text { Peak 3: } & 0.00 & 0.0 & 0.00\end{array}$

Size distribution by intensity

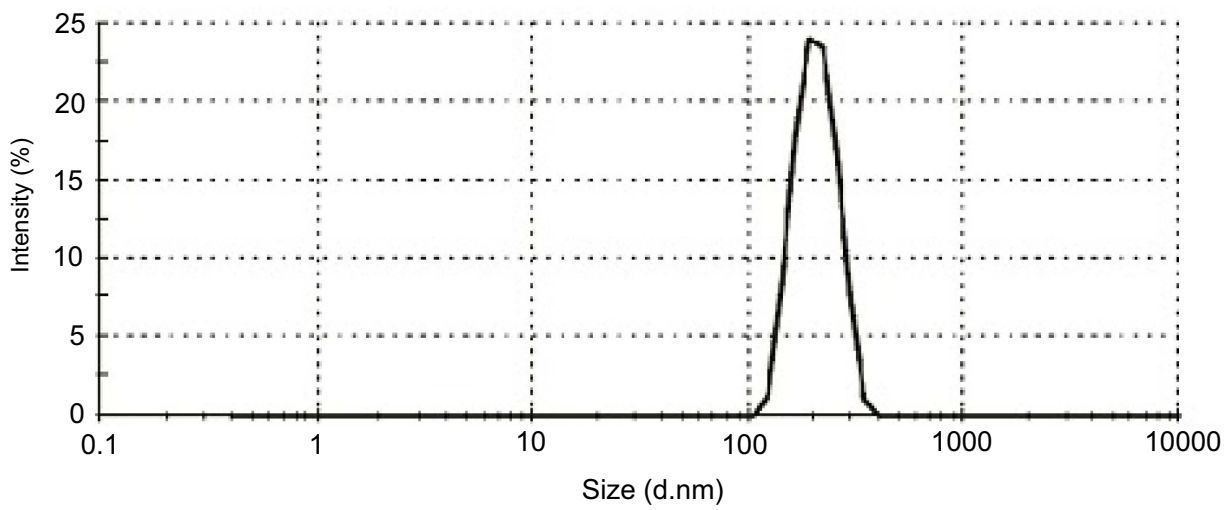

Figure I Size distribution by intensity for TPGS-NS and Tween-NS.

Abbreviations: TPGS, D- $\alpha$-tocopheryl polyethylene glycol I,000 succinate; NS, nanosuspension. 
TPGS and Tween 80 NSs while optimizing the factors that minimize particle size and its distribution. Annealing processes, including homogenization and sonication, are required to gain nanosized particles using precipitative procedures, as produced NPs commonly have a potent affinity to bind together in order to form a microscale structure. ${ }^{20,50}$

The particle size initially decreased at a homogenization pressure between 500 and 900 bar but slightly increased after 20 homogenization cycles. It should be noted that stabilizer damage and agglomeration might occur following higher homogenization pressures and more cycles, ${ }^{51}$ both of which increase the particle's size and distribution. As a result, a homogenization pressure of 900 bar and 20 cycles were chosen as optimal values.

Probe sonicator was employed to construct TPGS-NS with the optimized probe sonicator power, time and frequency. Elevating the ultrasonic power resulted in a reduced NS size, probably due to the impact of increased erosion on the surfaces of the large particles and agglomerates. The particle size is also affected by the duration of ultrasonication. In total, 15 mins were spent synthesizing NPs with dimensions of $<200 \mathrm{~nm}$ and with a narrow size distribution using ultrasonic power.
Therefore, the optimal conditions for successfully achieving the desired TPGS-NS were 15 mins and a vibration amplitude of $90 \%$ with the frequency of one in an ice bath to maintain the production temperature.

\section{Physicochemical characteristics of curcumin NS}

Reducing of embolism risk and sterilization via filtration $(0.22 \mu \mathrm{m})$ can be obtained using a narrow size distribution and mean particle diameter of $200 \mathrm{~nm} .{ }^{52}$ Unimodal distribution was observed for both NSs (Figure 1). The Z-average means were $199 \pm 2.5$ and $193 \pm 8 \mathrm{~nm}$ and the PDI values were $0.2 \pm 0.01$ and $0.2 \pm 0.03$ for the TPGS and Tween 80 NSs, respectively. To avoid particle growth due to various saturation solubility in particles of different sizes, such as that caused by Ostwald ripening, it is essential to achieve a narrow size distribution confirmed by a small PDI value. ${ }^{53}$ The zeta potentials were -15.2 \pm 3.3 and $-12.9 \pm 1.7 \mathrm{mV}$ for the TPGS and Tween $80-\mathrm{NSs}$, respectively. A physically stable NS was reportedly produced with a zeta potential of at least $-30 \mathrm{mV}$ for
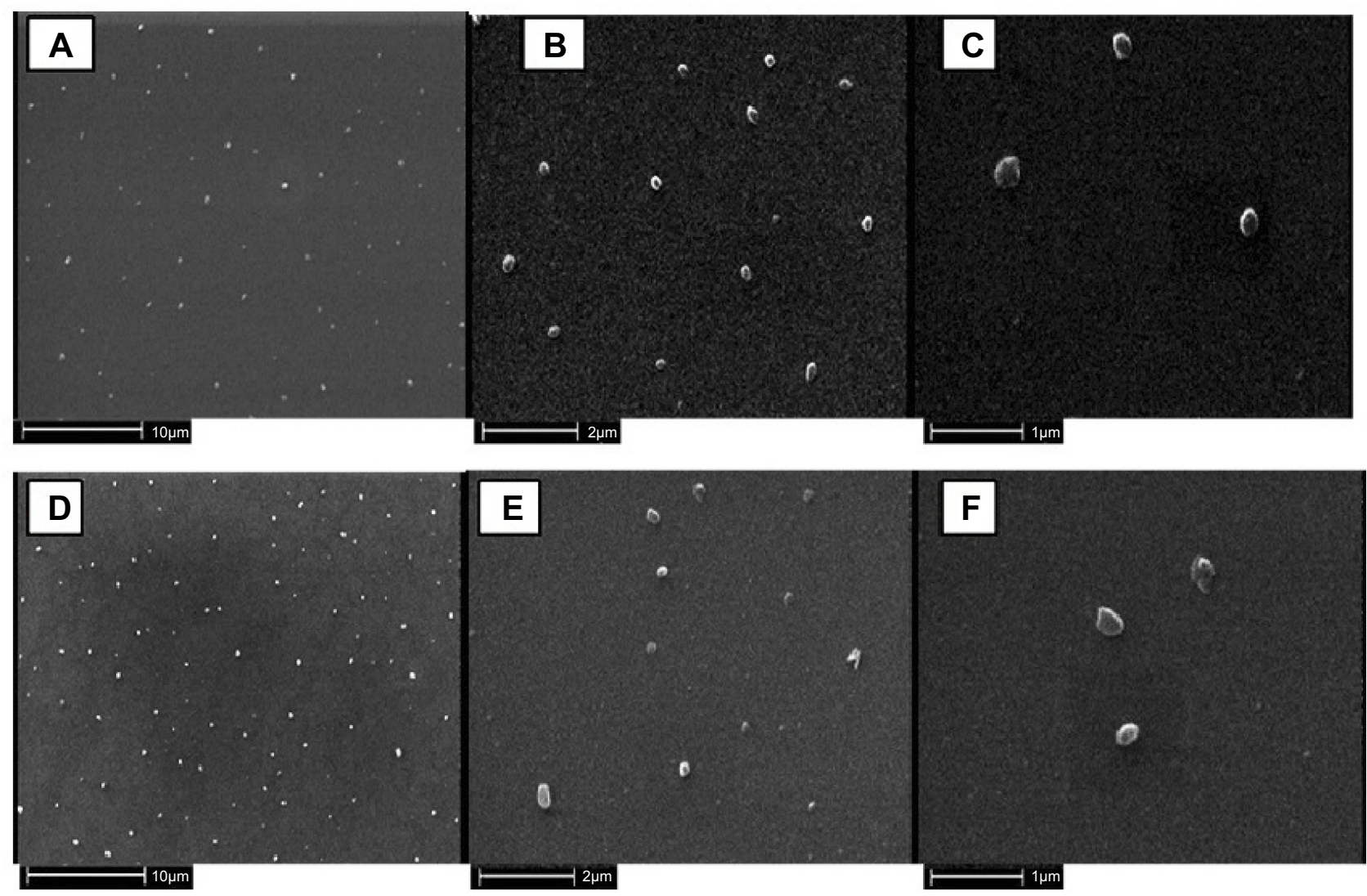

Figure 2 SEM photographs of curcumin nanosuspensions: TPGS-NS (A-C) and Tween-NS (D-F).

Abbreviations: TPGS, D- $\alpha$-tocopheryl polyethylene glycol I,000 succinate; NS, nanosuspension; TPGS-NS, curcumin and TPGS; Tween-NS, curcumin and Tween 80. 
electrostatically stabilized systems and $-20 \mathrm{mV}$ for sterically stabilized systems, ${ }^{54}$ highlighting the necessity of a relatively stable formulation.

The morphologies of NSs were studied using a scanning electron microscope. The images of the curcumin NSs are shown in Figure 2, images A-F. NSs were approximately spherical with smooth surfaces and sizes of about $150 \mathrm{~nm}$ as can be observed using SEM. No evidence of drug crystals or fragments was also observed. Since preparing the samples for the SEM resulted in shrinking the NSs, the measured size was smaller compared to that of the DLS. In fact, the images taken with the SEM were taken without using a solvent, while DLS displays the hydrodynamic diameter or the equivalent sphere diameter in a solution. ${ }^{25}$

No XRD analyses were performed on Tween 80 because it is liquid at room temperature. A significant crystallinity was seen for pure curcumin based on diffraction peaks between $2 \mathrm{\Theta}$ values of $5^{\circ} \mathrm{C}$ and $30^{\circ} \mathrm{C}$ (Figure 3), but less intense crystallinity was seen for curcumin NSs without a stabilizer based on diffraction peaks between $2 \Theta$ values of $5^{\circ} \mathrm{C}$ and $30^{\circ} \mathrm{C}$. Very low intensities resulted in
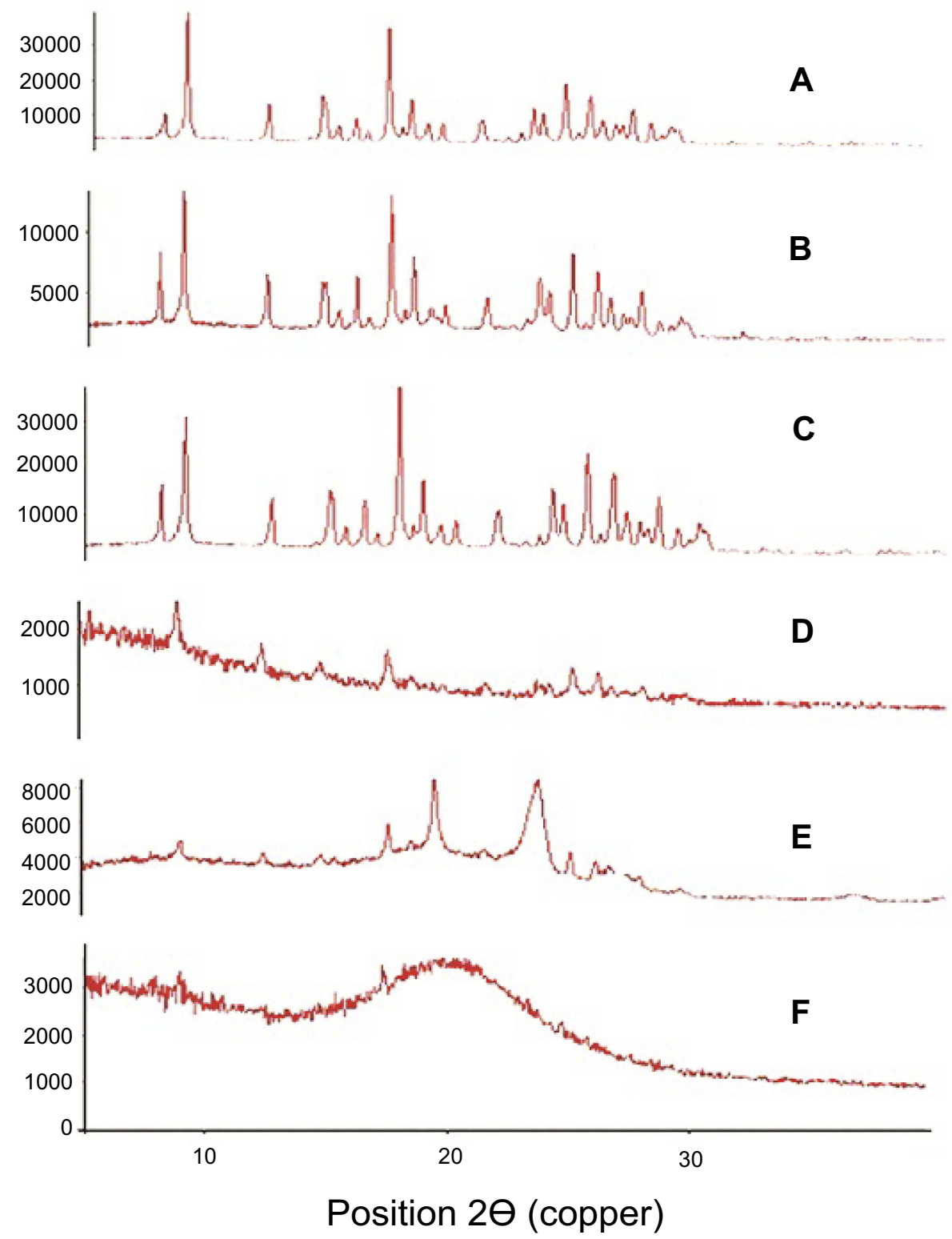

Figure 3 X-ray powder diffractometry (A) of curcumin, (B) physical mixture of TPGS solution and curcumin, (C) physical mixture of Tween solution and curcumin, (D) NS without surfactant, (E) Tween-NS, and (F) TPGS-NS.

Abbreviations: TPGS, D- $\alpha$-tocopheryl polyethylene glycol I,000 succinate; NS, nanosuspension. 
TPGS-stabilized formulation peaks at 17.3 and 20.8, indicating the amorphous nature of TPGS-NS and suggesting that curcumin molecularly dispersed in TPGS. Diffraction peaks between $2 \Theta$ values of $5^{\circ} \mathrm{C}$ and $30^{\circ} \mathrm{C}$ were reported for Tween 80-stabilized formulations; however, less intensity was gained compared to the pure curcumin. This shows the non-molecular dispersion of curcumin in Tween 80. Nanonization caused a reduction in crystallinity, ${ }^{55}$ with an order of crystallinity reduction as follows: native curcumin $>$ a physical mixture of Tween 80 and curcumin $>$ a physical mixture of TPGS and curcumin $>$ Tween-NS $>$ NS without surfactant $>$ TPGS-NS.

Based on ANOVA test, both NSs did not show the significant size and PDI increases during stability study at $4{ }^{\circ} \mathrm{C}$ on predetermined days $(P$-value $<0.05)$.

Dissolution profiles of curcumin NSs and pure curcumin are shown in Figure 4. Although TPGS-NS according to its amorphous state was dissolved faster, both nanosuspensions were dissolved completely during 30 mins. Less than $30 \%$ of pure curcumin was dissolved during this tilme.

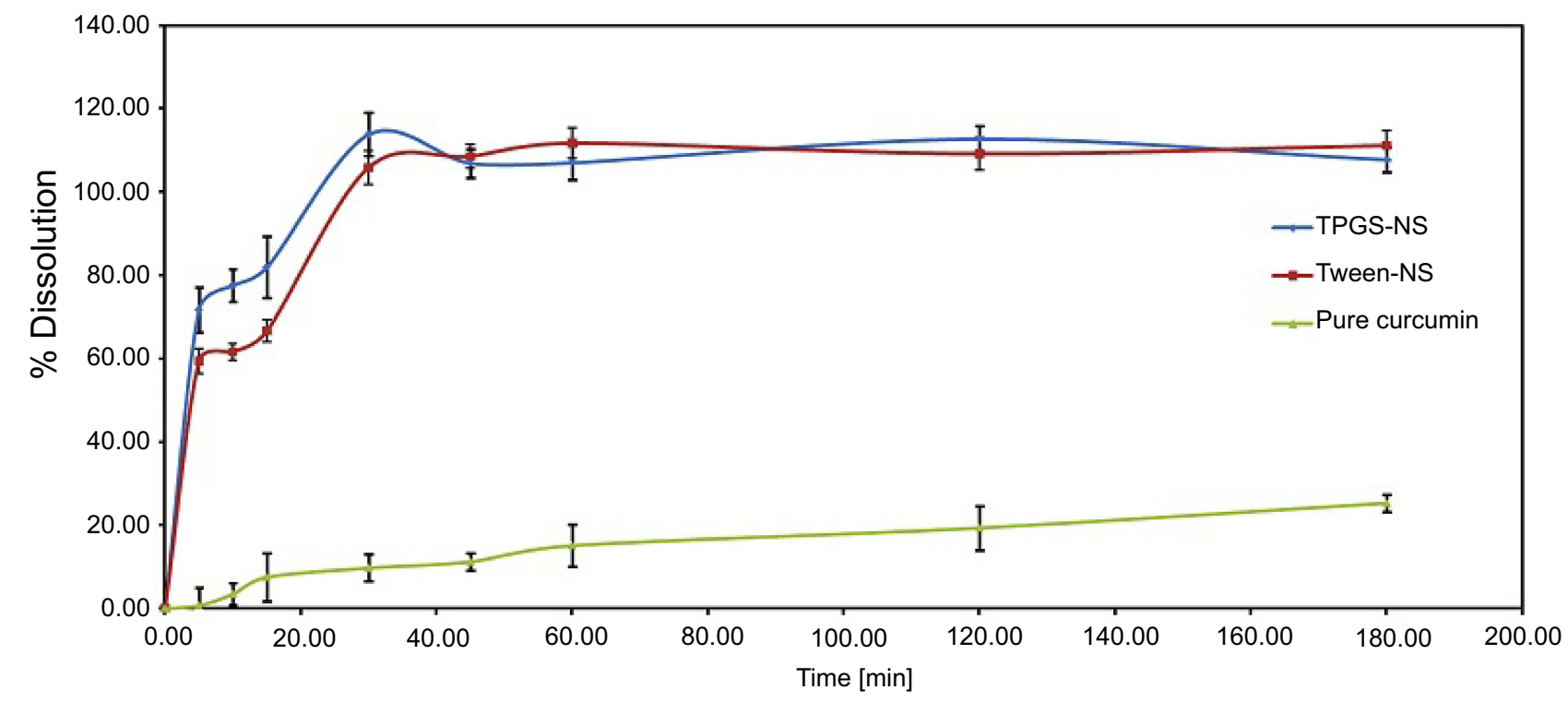

Figure 4 Dissolution curve of the TPGS-NS, Tween-NS and pure curcumin. All values reported are means $\pm S E(n=3)$.

Abbreviations: TPGS, D- $\alpha$-tocopheryl polyethylene glycol I,000 succinate; NS, nanosuspension; TPGS-NS, curcumin and TPGS; Tween-NS, curcumin and Tween 80.

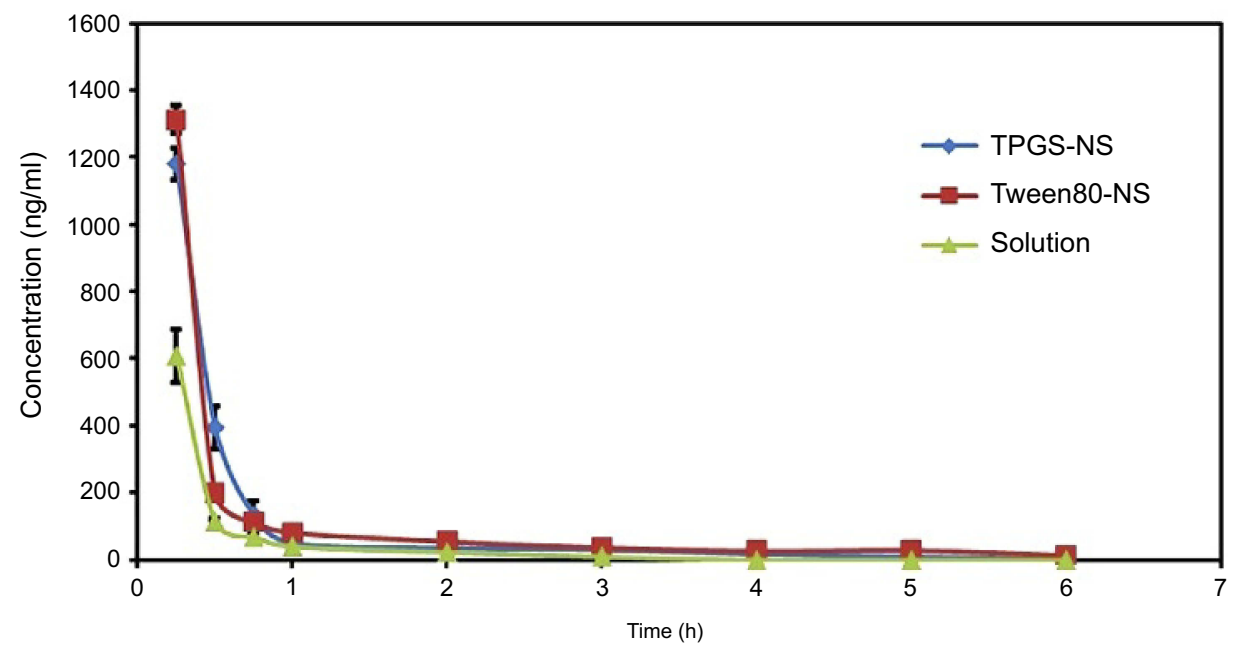

Figure 5 Plasma concentration of solution and NSs in rat. All values reported are means $\pm S E(n=6)$. ( $\bullet$ TPGS-NS, $\boldsymbol{n}$ Tween-NS, - solution).

Abbreviations: TPGS, D- $\alpha$-tocopheryl polyethylene glycol I,000 succinate; NS, nanosuspension; TPGS-NS, curcumin and TPGS; Tween-NS, curcumin and Tween 80; Solution, DMA, PEG 400, and isotonic dextrose solution. 


\section{Chromatographic assay}

A stable baseline and proper resolution between curcumin and endogenous compounds were observed in plasma and various tissues. Curcumin had a retention time of 13 mins. Curcumin measurements for quantification in plasma and organs were in the limits of $5 \mathrm{ng} / \mathrm{mL}$. A good linearity $\left(\mathrm{R}^{2}=0.9996\right)$ was obtained for the plasma calibration curve ranging $5-500 \mathrm{ng} / \mathrm{mL}$. For all studied organs, the standard curves with curcumin concentrations $(5-500 \mathrm{ng} / \mathrm{mL})$ revealed good linearity and correlation coefficients of 0.9972-0.9997 within this concentration range. Curcumin at high, intermediate, and low concentration showed recovery rates of $80-95 \%$ and $84-94 \%$ for tissues and plasma, respectively. All of the accuracy and precision values for both intra- and inter-assays were within $15 \%$ for curcumin in organs and plasma.

\section{In vivo pharmacokinetic study}

A noncompartment model was used to describe the pharmacokinetics of curcumin-NSs and curcumin solution following i.v. administration in rats. Figure 5 depicts the average plasma concentration of curcumin in rat administered intravenously with both curcumin solution and NS formulations at a single dose of $10 \mathrm{mg} / \mathrm{kg}$. Table 1 summarizes the pharmacokinetic parameters. The plasma concentration-time profiles indicate that drug NSs could effectively increase curcumin plasma levels in comparison with curcumin solution. The pharmacokinetic profile in the rats showed a sharp reduction in the plasma concentration of curcumin within $1 \mathrm{hr}$ of the intravenous administration of curcumin-NS, which may be due to the rapid uptake of the slowly dissolving curcumin-NS by the RES. Studies have reported that slowly dissolving NSs are ingested by the phagocytes of the MPS, mainly the Kupffer cells found in the liver, spleen, and lungs. ${ }^{56,57}$ The dissolved NSs are able to pass through the phagolysosomal membrane because of their lipophilic character; they leave the cellular vesicle, penetrate the cytoplasm, and then exit the cell by diffusing down the drug concentration gradient. $^{57}$ Accordingly, the half-life of curcumin-NSs is increased, which leads to prolonged curcumin-NSs presence after their administration. Maximum concentrations $\left(\mathrm{C}_{\max }\right)$ of TweenNS $(1311.6 \pm 172.3 \mathrm{ng} / \mathrm{mL})$ and TPGS-NS $(1121.3 \pm 46.3 \mathrm{ng} /$ $\mathrm{mL}$ ) in plasma were almost 2 and 1.7 fold, respectively, that of curcumin solution $(661.7 \pm 48.6 \mathrm{ng} / \mathrm{ml})(P$-value $<0.05)$. The values of $\mathrm{AUC}_{0 \text {-inf }}$ obtained for Tween-NS and TPGS-NS (1874.7 \pm 333.6 and $964.6 \pm 75.8 \mathrm{ng} . \mathrm{h} / \mathrm{mL}$, respectively) were roughly 2.6 and 1.3 times the curcumin solution (711.6 74.2 ng.h/mL). After 6 and 5 hrs of injecting Tween-NS and TPGSNS, respectively, it was still possible to detect curcumin plasma concentration, while this time was up to $3 \mathrm{hrs}$ for curcumin solution. Curcumin-NSs, therefore, preserved a longer retention time in blood than curcumin solution. As a result, significantly higher systemic exposure with higher AUCs was obtained by both NS preparations. Decreases in the $\mathrm{AUC}_{0 \text {-inf }}$ values followed a downward order of $\sim$ TweenNS $>\sim$ TPGS-NS $>\sim$ curcumin solution whereas the CL values showed no changes between different formulations.

\section{Biodistribution study}

Figure 6 shows the concentrations of curcumin in the tissues after intravenous administration of the curcumin NSs. At the studied time points, the concentrations of curcumin in the tissues from the curcumin-NSs were significantly higher compared with the curcumin solution, which is in agreement with the results observed in plasma.

Table I Pharmacokinetic parameters of curcumin after i.v. administration of curcumin solution and NSs at a dose of $10 \mathrm{mg} / \mathrm{kg}$ in rat (mean $\pm S E, n=6$ )

\begin{tabular}{|c|c|c|c|}
\hline Parameter & TPGS-NS & Tween-NS & Curcumin solution \\
\hline$K_{e l}(I / h)$ & $0.48 \pm 0.100$ & $0.39 \pm 0.048$ & $0.68 \pm 0.106$ \\
\hline $\mathbf{t}_{1 / 2}(\mathbf{h})$ & $1.45 \pm 0.180^{*}$ & $1.94 \pm 0.292 * *$ & $1.11 \pm 0.168$ \\
\hline$C_{\max }(n g / m L)$ & $1121.28 \pm 46.259 *$ & $|3| 1.62 \pm \mid 72.294 * *$ & $661.66 \pm 48.604$ \\
\hline AUC $_{0-\mathrm{t}}(\mathrm{ng} \cdot \mathrm{h} / \mathrm{mL})$ & $891.97 \pm 73.132$ & $1792.84 \pm 324.169 * *$ & $682.42 \pm 75.87 \mid$ \\
\hline$A U C_{0-\text { inf }}(\mathrm{ng} \cdot \mathrm{h} / \mathrm{mL})$ & $964.65 \pm 75.843^{*}$ & $1874.70 \pm 333.588 * *$ & $711.60 \pm 74.157$ \\
\hline AUMC $_{0-\text { inf }}\left(\mathrm{ng} \cdot \mathrm{h}^{2} / \mathrm{mL}\right)$ & $515.96 \pm 352.64$ & $1299.93 \pm 335.51 * *$ & $352.64 \pm 53.34$ \\
\hline MRT (h) & $0.61 \pm 0.050^{*}$ & $0.76 \pm 0.194$ & $0.53 \pm 0.107$ \\
\hline $\mathrm{Cl}(\mathrm{mg} / \mathrm{kg}) /(\mathrm{ng} / \mathrm{mL}) / \mathrm{h}$ & $0.011 \pm 0.001$ & $0.006 \pm 0.001$ & $0.015 \pm 0.002$ \\
\hline$V_{s s}(\mathrm{mg} / \mathrm{kg}) /(\mathrm{ng} / \mathrm{mL})$ & $0.006 \pm 0.001$ & $0.005 \pm 0.002$ & $0.008 \pm 0.002$ \\
\hline
\end{tabular}

Notes: *Significant difference compared at $P$-value $<0.05$ compared with curcumin solution. **Significant difference compared at $P$-value $<0.05$ compared with curcumin solution. Abbreviations: $C_{\max }$, maximum concentrations; $T_{\max }$, time of maximum concentrations, AUC, area under the curve, $\mathrm{t}_{\mathrm{l} / 2}$, half-Life, AUMC, area under the first moment curve; $\mathrm{Cl}$, clearance; MRT, mean residence time; $\mathrm{V}_{\mathrm{ss}}$, steady-state volume of distribution; TPGS, D- $\alpha$-tocopheryl polyethylene glycol I,000 succinate; NS, nanosuspension. 

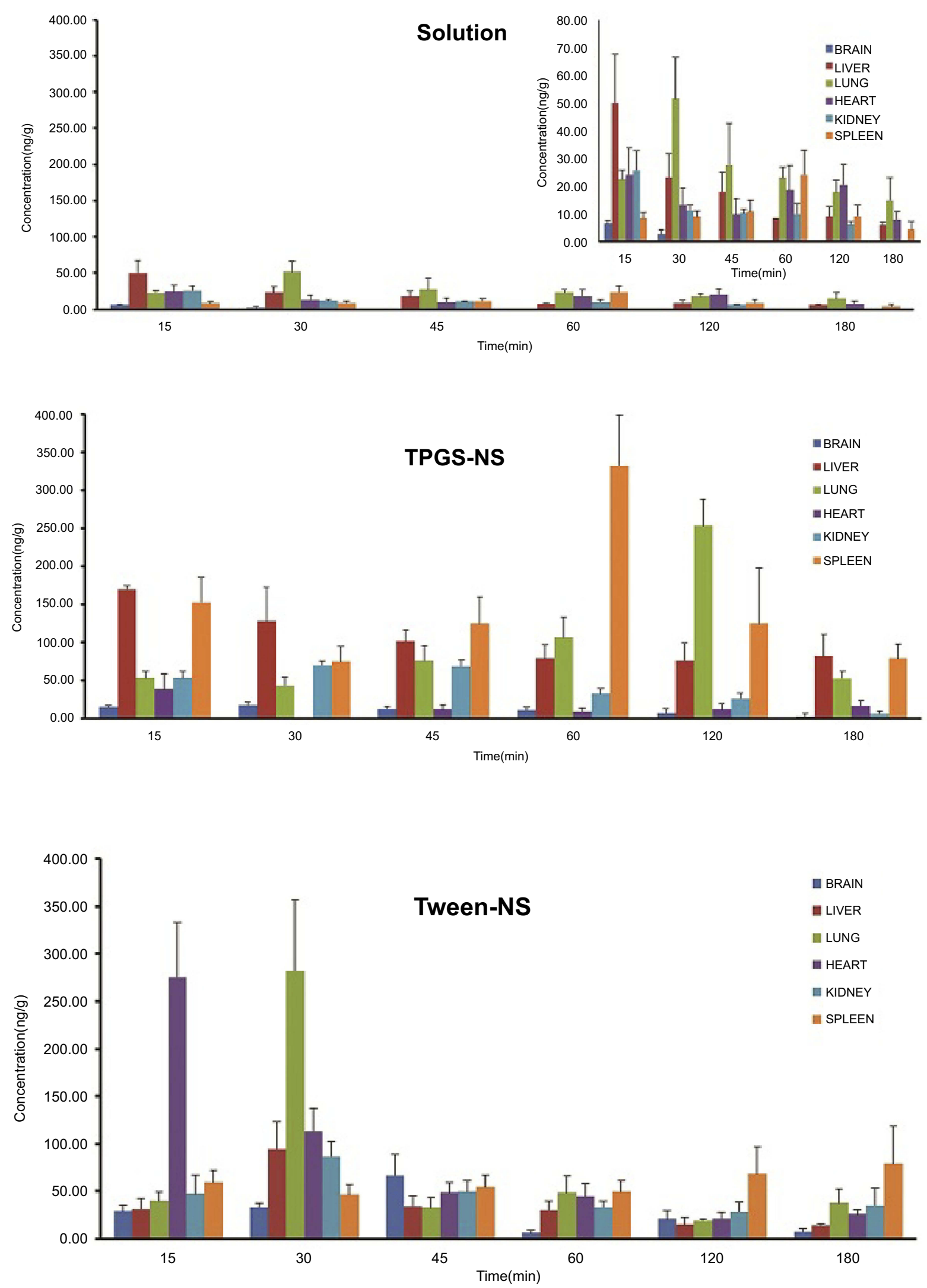

Figure 6 The tissue curcumin concentrations versus time after intravenous administration of solution and NSs. All values reported are means $\pm S E$ ( $n=6$ ).

Abbreviations: TPGS, D- $\alpha$-tocopheryl polyethylene glycol I,000 succinate; NS, nanosuspension; TPGS-NS, curcumin and TPGS; Tween-NS, curcumin and Tween 80; Solution, DMA, PEG 400, and isotonic dextrose solution. 
Table 2 summarizes the pharmacokinetic parameters. In this study, the intravenous injection of curcumin solution produced a high concentration of curcumin in the lungs $(50.0 \mathrm{ng} / \mathrm{mL})$, which was consistent with the results of a similar reported study by Gao et al. ${ }^{58}$ The $\mathrm{AUC}_{0.25-3}$ for the curcumin concentration in heart, liver, spleen, kidney, and brain ranged from 5 to $45 \mathrm{ng} . \mathrm{h} / \mathrm{g}$. The relatively high concentration of curcumin solution or curcumin-NSs in the lungs was related to the high blood perfusion rate and large surface area of lung. ${ }^{59,60}$

The spleen, lung, and liver showed higher levels of TPGSNS $(P$-value $<0.05)$ compared with curcumin solution; this agrees with the results of previous research on tissue biodistribution of curcumin-NS using TPGS as a stabilizer. ${ }^{58}$ On the other hand, the lung showed higher levels of Tween-NS ( $P$ value $<0.05$ ). The pegylation and block copolymers on the NPs surface may delay, but not prevent, the clearance from the blood. However, the RES (liver, spleen, and lung) may have been unable to capture the NPs coated with TPGS or Tween 80 due to the lower affinity of the MPS toward the hydrophilic surface and steric repulsion effect, respectively, of the modified NPs, which resulted in the opsonization or rapid clearance of the particles from the body. ${ }^{61}$ So in non-RES organs, such as heart and brain, curcumin levels enhanced significantly. As shown in the figures (Figure 7), Tween-NS significantly increased the curcumin concentration in the brain $(P$-value $<0.05)$ compared with the curcumin solution and TPGS-NS. Additionally, the $\mathrm{AUC}_{0.25-3}$ in the brain was

Table 2 Pharmacokinetic parameters of curcumin after i.v. administration of curcumin solution and NSs in different organs at a dose of $10 \mathrm{mg} / \mathrm{kg}$ (mean, $\mathrm{n}=6)$

\begin{tabular}{|c|c|c|c|c|c|c|}
\hline Formulation/parameters & Brain & Liver & Lung & Heart & Kidney & Spleen \\
\hline \multicolumn{7}{|l|}{ Curcumin solution } \\
\hline $\mathrm{AUC}_{0.25-3}(\mathrm{ng} . \mathrm{h} / \mathrm{g})$ & 5.1 & 33.8 & 62.5 & 45.0 & 21.1 & 32.5 \\
\hline $\mathrm{C}_{\max }(\mathrm{ng} / \mathrm{g})$ & 6.6 & 50.0 & 51.6 & 24.1 & 25.7 & 24.0 \\
\hline $\mathrm{T}_{\max }(\mathrm{h})$ & 0.25 & 0.25 & 0.50 & 0.25 & 0.25 & 1.00 \\
\hline \multicolumn{7}{|l|}{ TPGS-NS } \\
\hline $\mathrm{AUC}_{0.25-3}(\mathrm{ng} \cdot \mathrm{h} / \mathrm{g})$ & 24.3 & 245.2 & 382.9 & 19.5 & 90.6 & 440.9 \\
\hline $\mathrm{C}_{\max }(\mathrm{ng} / \mathrm{g})$ & 17.7 & 169.8 & 253.4 & 38.7 & 70.1 & 333.0 \\
\hline $\mathrm{T}_{\max }(\mathrm{h})$ & 0.50 & 0.25 & 2.00 & 0.25 & 0.50 & 1.00 \\
\hline \multicolumn{7}{|l|}{ Tween-NS } \\
\hline $\mathrm{AUC}_{0.25-3}(\mathrm{ng} \cdot \mathrm{h} / \mathrm{g})$ & 57.0 & 77.5 & 152.8 & 137.3 & 107.0 & 171.8 \\
\hline $\mathrm{C}_{\max }(\mathrm{ng} / \mathrm{g})$ & 66.7 & 94.5 & 282.1 & 275.5 & 86.5 & 79.4 \\
\hline $\mathrm{T}_{\max }(\mathrm{h})$ & 0.75 & 0.50 & 0.50 & 0.25 & 0.50 & 3.00 \\
\hline
\end{tabular}

Abbreviations: $C_{\max }$, maximum concentrations; $T_{\max }$, time of maximum concentrations; AUC, area under the curve; TPGS, D- $\alpha$-tocopheryl polyethylene glycol I,000 succinate; NS, nanosuspension.

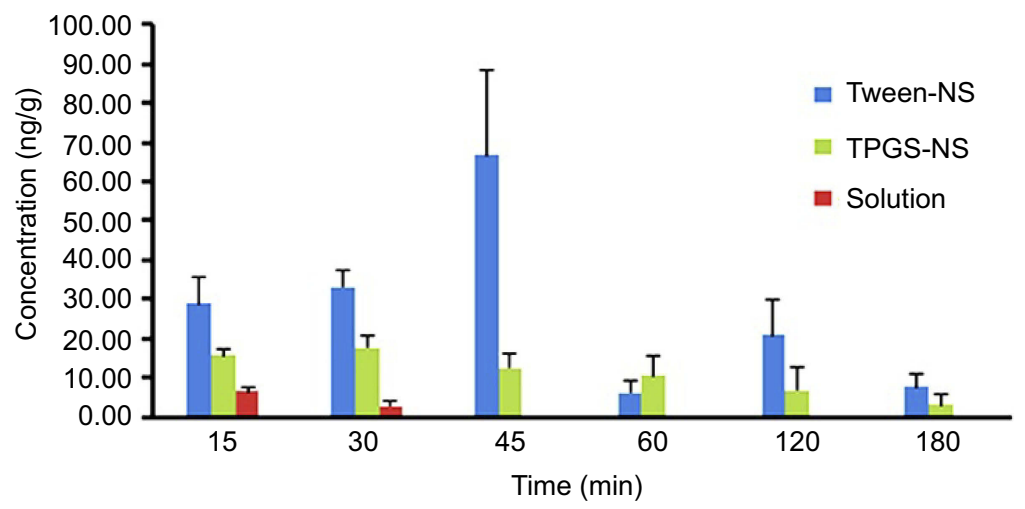

Figure 7 Brain curcumin concentrations versus time after intravenous administration of solution and NSs. All values reported are means \pm SE ( $n=6$ ).

Abbreviations: TPGS, D- $\alpha$-tocopheryl polyethylene glycol I,000 succinate; NS, nanosuspension; TPGS-NS, curcumin and TPGS; Tween-NS, curcumin and Tween 80; Solution, DMA, PEG 400, and isotonic dextrose solution. 
57.0, 24.3, and 5.1 ng/g.h for the Tween 80-NS, TPGS-NS, and curcumin solution, respectively $(P$-value $<0.05)$. The interaction of the injected external particles with the plasma proteins and the cells could strongly determine the fate of particles. ${ }^{61}$ Polysorbates $20,40,60$, and 80 , poloxamer, poloxamine, and Cremophor EZ, and RH-40 are some surfactants that have been examined as surface-coating candidates for the brain targeting of NPs. However, the most effective surfacecoating material for accelerating the delivery of NPs to the brain was reported to be polysorbate $80 .{ }^{62}$ Studies found that, following intravenous injection, ApoE and/or B are absorbed by Tween 80 -coated NPs from the blood, which indicated that NPs functioned as LDLs and were capable of interacting with the brain capillary endothelial cells and transferring into the brain using receptor-mediated endocytosis. ${ }^{28,62}$ The results of the present study showed a higher distribution of TPGS-NS to the brain compared with the curcumin solution $(P$-value $<0.05)$; however, this distribution was lower than that of Tween-NS $(P$-value $<0.05)$. According to the reports, the nonspecific absorption through the adsorptive-mediated endocytic pathway could effectively increase the cellular uptake of the TPGS micelles to the brain. ${ }^{41}$

\section{Conclusion}

Curcumin is a multipurpose compound with multiple characteristics. Its efficacy is associated with its bioavailability at the targeted site. According to in vivo studies, the surface-coating is one of the leading factors that significantly affect the biodistribution of NSs following intravenous administration. Certain organs can be targeted by relatively high drug loading NS that have been stabilized with surfactants or polymeric steric stabilizers. We examined the effects of a stabilizer on the biodistribution of a NS drug delivery system after IV administration. The surface of the NPs was coated with TPGS and Tween 80 using physical adsorption. This simple approach gave stability to the suspension and sustained the bioactivity. A significant in vivo enhancement was observed in the distribution of TweenNS in the brain tissues. The spleen, lung, and liver showed higher levels of TPGS-NS. According to the results obtained from the present study, it can be concluded that the surfacecoating can change the uptake pattern of the particles and Tween-NS significantly increased the curcumin concentration in the brain compared with the curcumin solution and TPGS-NS.

\section{Abbreviation list}

Tween-NS, Tween 80-coated nanosuspension; Apo E, apolipoprotein E; LDL, low-density lipoprotein; TPGS-NS,
TPGS coated nanosuspension; Log P, partition coefficient; NSs, nanosuspensions; MPS, mononuclear phagocytic system; BBB, blood-brain barrier; NPs, nanoparticles; TPGS, D- $\alpha$-tocopheryl polyethylene glycol 1,000 succinate; PVP, polyvinylpyrrolidone; HPMC, hydroxypropyl methylcellulose; DMA, dimethyl acetamide; PDI, poly dispersity index; XRD, X-ray powder diffractometry; SEM, scanning electron microscopy; RES, reticuloendothelial system; $\mathrm{C}_{\text {max }}$, maximum concentrations; $\mathrm{T}_{\max }$, time of maximum concentrations; AUC, area under the curve; $t_{1 / 2}$, half-life; AUMC, area under the first moment curve; $\mathrm{Cl}$, clearance; $\mathrm{MRT}$, mean residence time; $\mathrm{V}_{\mathrm{ss}}$, steady-state volume of distribution.

\section{Acknowledgment}

The Pharmaceutical Sciences Research Centre of Tehran University of Medical Sciences supported this study by a grant.

\section{Disclosure}

The authors report no conflicts of interest in this work.

\section{References}

1. Rachmawati H, Safitri D, Pradana A, Adnyana I. TPGS-stabilized curcumin nanoparticles exhibit superior effect on carrageenan-induced inflammation in wistar rat. Pharmaceutics. 2016;8(3). doi:10.3390/ pharmaceutics 8030024

2. Anand P, Sundaram C, Jhurani S, Kunnumakkara AB, Aggarwal BB. Curcumin and cancer: an "old-age" disease with an "age-old" solution. Cancer Lett. 2008;267(1):133-164. doi:10.1016/j.canlet.2008.03.025

3. Adahoun, M.A.A., Al-Akhras MH, Jaafar MS, Bououdina M. Enhanced anti-cancer and antimicrobial activities of curcumin nanoparticles. Artif Cells Nanomed Biotechnol. 2017;45(1):98-107. doi:10.3109/21691401.2015.1129628

4. Khan, S., Imran M, Butt TT, et al. Curcumin based nanomedicines as efficient nanoplatform for treatment of cancer: new developments in reversing cancer drug resistance, rapid internalization, and improved anticancer efficacy. Trends Food Sci Technol. 2018;80:8-22. doi: https://doi.org/10.1016/j.tifs.2018.07.026

5. Dong J, Tao L, Abourehab MAS, Hussain Z. Design and development of novel hyaluronate-modified nanoparticles for combo-delivery of curcumin and alendronate: fabrication, characterization, and cellular and molecular evidences of enhanced bone regeneration. Int $J$ Biol Macromol. 2018;116:1268-1281. doi:10.1016/j.ijbiomac.2018.05.116

6. Hussain Z, Thu HE, Ng S-F, Khan S, Katas H. Nanoencapsulation, an efficient and promising approach to maximize wound healing efficacy of curcumin: a review of new trends and state-of-the-art. Colloid Surf B Biointerfaces. 2017;150:223-241. doi:10.1016/j. colsurfb.2016.11.036

7. Goel A, Kunnumakkara AB, Aggarwal BB. Curcumin as "Curecumin": from kitchen to clinic. Biochem Pharmacol. 2008;75(4):787-809. doi:10.1016/j.bcp.2007.08.016

8. Garcia-Alloza M, Borrelli LA, Rozkalne A, Hyman BT, Bacskai BJ. Curcumin labels amyloid pathology in vivo, disrupts existing plaques, and partially restores distorted neurites in an Alzheimer mouse model. J Neurochem. 2007;102(4):1095-1104. doi:10.1111/ j.1471-4159.2007.04613.x 
9. Mathew, A, Fukuda, T, Nagaoka, Y, et al. Curcumin loaded-PLGA nanoparticles conjugated with Tet-1 peptide for potential use in Alzheimer's disease. PLoS One. 2012;7(3):e32616. doi:10.1371/journal.pone. 0032616

10. Sumanont Y, Murakami Y, Tohda M, Vajragupta O, Watanabe H, Matsumoto K. Effects of manganese complexes of curcumin and diacetylcurcumin on kainic acid-induced neurotoxic responses in the rat hippocampus. Biol Pharm Bull. 2007;30(9):1732-1739. doi: https://doi.org/10.1248/bpb.30.1732

11. Purkayastha S, Berliner A, Fernando SS, et al. Curcumin blocks brain tumor formation. Brain Res. 2009;1266:130-138. doi:10.1016/j. brainres.2009.01.066

12. Kakkar V, Muppu SK, Chopra K, Kaur IP. Curcumin loaded solid lipid nanoparticles: an efficient formulation approach for cerebral ischemic reperfusion injury in rats. Eur $J$ Pharm Biopharm. 2013;85(3 Pt A):339-345. doi:10.1016/j.ejpb.2013.02.005

13. Kunnumakkara AB, Bordoloi D, Padmavathi G, et al. Curcumin, the golden nutraceutical: multitargeting for multiple chronic diseases. $\mathrm{Br}$ J Pharmacol. 2017;174(11):1325-1348. doi:10.1111/bph.13621

14. Anand P, Kunnumakkara AB, Newman RA, Aggarwal BB. Bioavailability of curcumin: problems and promises. Mol Pharm. 2007;4(6):807-818. doi:10.1021/mp700113r

15. Patravale V, Kulkarni R. Nanosuspensions: a promising drug delivery strategy. J Pharm Pharmacol. 2004;56(7):827-840. doi:10.1211/ 0022357023691

16. Agrawal, M., Tripathi DK, Saraf S, et al. Recent advancements in liposomes targeting strategies to cross blood-brain barrier (BBB) for the treatment of Alzheimer's disease. $J$ Control Release. 2017;260:61-77. doi:10.1016/j.jconrel.2017.05.019

17. Kedar U, Phutane P, Shidhaye S, Kadam V. Advances in polymeric micelles for drug delivery and tumor targeting. Nanomedicine. 2010;6(6):714-729. doi:10.1016/j.nano.2010.05.005

18. Singh, Y, Meher JG, Raval K, et al. Nanoemulsion: concepts, development and applications in drug delivery. $J$ Control Release 2017;252:28-49. doi:10.1016/j.jconrel.2017.03.008

19. Li Y, Wu Z, He W, et al. Globular protein-coated Paclitaxel nanosuspensions: interaction mechanism, direct cytosolic delivery, and significant improvement in pharmacokinetics. Mol Pharm. 2015;12 (5):1485-1500. doi:10.1021/mp5008037

20. Keck CM, Müller RH. Drug nanocrystals of poorly soluble drugs produced by high pressure homogenisation. Eur J Pharm Biopharm. 2006;62(1):3-16. doi:10.1016/j.ejpb.2005.05.009

21. Wang Y, Zheng Y, Zhang L, Wang Q, Zhang D. Stability of nanosuspensions in drug delivery. $J$ Control Release. 2013;172(3):11261141. doi:10.1016/j.jconrel.2013.08.006

22. Constantinides PP, Chaubal MV, Shorr R. Advances in lipid nanodispersions for parenteral drug delivery and targeting. Adv Drug Deliv Rev. 2008;60(6):757-767. doi:10.1016/j.addr.2007.10.013

23. Müller RH, Gohla S, Keck CM. State of the art of nanocrystalsspecial features, production, nanotoxicology aspects and intracellular delivery. Eur J Pharm Biopharm. 2011;78(1):1-9. doi:10.1016/j. ejpb.2011.01.007

24. Xiong R, Lu W, Yue P, et al. Distribution of an intravenous injectable nimodipine nanosuspension in mice. J Pharm Pharmacol. 2008;60 (9):1155-1159. doi:10.1211/jpp.60.9.0006

25. Han M, Liu X, Guo Y, Wang Y, Wang X. Preparation, characterization, biodistribution and antitumor efficacy of hydroxycamptothecin nanosuspensions. Int J Pharm. 2013;455(1-2):85-92. doi:10.1016/j. ijpharm.2013.07.056

26. Kreuter J, Shamenkov D, Petrov V, et al. Apolipoproteinmediated transport of nanoparticle-bound drugs across the blood-brain barrier. $J$ Drug Target. 2002;10(4):317-325. doi:10.1080/10611860290031877

27. Kreuter J. Nanoparticulate systems for brain delivery of drugs. $A d v$ Drug Deliv Rev. 2001;47(1):65-81. doi:https://doi.org/10.1016/ S0169-409X(00)00122-8
28. Kulkarni SA, Feng SS. Effects of surface modification on delivery efficiency of biodegradable nanoparticles across the blood-brain barrier. Nanomedicine (Lond). 2011;6(2):377-394. doi:10.2217/nnm.10.131

29. Ishak RAH, Mostafa NM, Kamel AO. Stealth lipid polymer hybrid nanoparticles loaded with rutin for effective brain delivery - comparative study with the gold standard (Tween 80): optimization, characterization and biodistribution. Drug Deliv. 2017;24(1):18741890. doi:10.1080/10717544.2017.1410263

30. Gan CW, Feng SS. Transferrin-conjugated nanoparticles of poly(lactide)D-alpha-tocopheryl polyethylene glycol succinate diblock copolymer for targeted drug delivery across the blood-brain barrier. Biomaterials. 2010;31(30):7748-7757. doi:10.1016/j.biomaterials.2010.06.053

31. Lu W, Tan Y-Z, Hu K-L, Jiang X-G. Cationic albumin conjugated pegylated nanoparticle with its transcytosis ability and little toxicity against blood-brain barrier. Int $J$ Pharm. 2005;295(1-2):247-260. doi:10.1016/j.ijpharm.2005.01.043

32. Saraiva C, Praça C, Ferreira R, Santos T, Ferreira L, Bernardino L. Nanoparticle-mediated brain drug delivery: overcoming blood-brain barrier to treat neurodegenerative diseases. $J$ Control Release. 2016;235:34-47. doi:10.1016/j.jconrel.2016.05.044

33. Ahire E, Thakkar S, Darshanwad M, Misra M. Parenteral nanosuspensions: a brief review from solubility enhancement to more novel and specific applications. Acta Pharm Sin B. 2018;8:733-755. doi:10.1016/j.apsb.2018.07.011

34. Wang Y, Miao X, Sun L, et al. Effects of nanosuspension formulations on transport, pharmacokinetics, in vivo targeting and efficacy for poorly water-soluble drugs. Curr Pharm Des. 2014;20(3):454473. doi:10.2174/13816128113199990403

35. Muller RH, Jacobs C, Kayser O. Nanosuspensions as particulate drug formulations in therapy. Rationale for development and what we can expect for the future. Adv Drug Deliv Rev. 2001;47(1):3-19. doi: https://doi.org/10.1016/S0169-409X(00)00118-6

36. Wong HL, Wu XY, Bendayan R. Nanotechnological advances for the delivery of CNS therapeutics. Adv Drug Deliv Rev. 2012;64(7):686700. doi:10.1016/j.addr.2011.10.007

37. Calvo, P, Gouritin B, Chacun H, et al. Long-circulating PEGylated polycyanoacrylate nanoparticles as new drug carrier for brain delivery. Pharm Res. 2001;18(8):1157-1166. doi:10.1023/A:1010931127745

38. Gelperina, S., Maksimenko O, Khalansky A, et al. Drug delivery to the brain using surfactant-coated poly (lactide-co-glycolide) nanoparticles: influence of the formulation parameters. Eur $J$ Pharm Biopharm. 2010;74(2):157-163. doi:10.1016/j.ejpb.2009.09.003

39. Goppert TM, Muller RH. Polysorbate-stabilized solid lipid nanoparticles as colloidal carriers for intravenous targeting of drugs to the brain: comparison of plasma protein adsorption patterns. J Drug Target. 2005;13(3):179-187. doi:10.1080/10611860500071292

40. Zhang Z, Tan S, Feng -S-S. Vitamin E TPGS as a molecular biomaterial for drug delivery. Biomaterials. 2012;33(19):4889-4906. doi:10.1016/j.biomaterials.2012.03.046

41. Meng, X., Liu J, Yu X, Li J, Lu X, Shen T. Pluronic F127 and Dalpha-Tocopheryl Polyethylene Glycol Succinate (TPGS) mixed micelles for targeting drug delivery across the blood brain barrier. Sci Rep. 2017;7(1):2964. doi:10.1038/s41598-017-03123-y

42. Sander JRG, Zeiger BW, Suslick KS. Sonocrystallization and sonofragmentation. Ultrason Sonochem. 2014;21(6):1908-1915. doi:10.1016/j.ultsonch.2014.02.005

43. Hau J, Van Hoosier GL. Animal research ethics. In: Olsson IAS, Robinson P, Pritchett K, Sandoe P, editors. Handbook of Laboratory Animal Science. Boca Raton: CRC Press; 2003:13-31.

44. Hau J, Van Hoosier GL. An overview of global legislation, regulations and policies on the use of animals for scientific research, testing, or education. In: Bayne K, de Greeve P, editors. Handbook of Laboratory Animal Science. Boca Raton: CRC Press; 2003:31-42.

45. Naiini A, Rabani M. Institutional Policies and Responsibilities. Animal Rights according to Quran Viewpoints. Quarterly periodical of Shahed University. 1999;26:43-50. Persian. 
46. Waynforth HB, Flecknell PA. Experimental and Surgical Technique in the Rat. Cambridge: Academic Press; 1980.

47. Zhang Y, Huo M, Zhou J, Xie S. PKSolver: an add-in program for pharmacokinetic and pharmacodynamic data analysis in microsoft excel. Comput Methods Programs Biomed. 2010;99(3):306-314. doi:10.1016/j.cmpb.2010.01.007

48. Rabinow BE. Nanosuspensions in drug delivery. Nat Rev Drug Discov. 2004;3(9):785-796. doi:10.1038/nrd1494

49. Rachmawati H, Al Shaal L, Müller RH, Keck CM. Development of curcumin nanocrystal: physical aspects. J Pharm Sci. 2013;102 (1):204-214. doi:10.1002/jps.23335

50. Xia, D, Quan P, Piao H, et al. Preparation of stable nitrendipine nanosuspensions using the precipitation-ultrasonication method for enhancement of dissolution and oral bioavailability. Eur J Pharm Sci. 2010;40(4):325-334. doi:10.1016/j.ejps.2010.04.006

51. Xu, Y, Liu X, Lian R, et al. Enhanced dissolution and oral bioavailability of aripiprazole nanosuspensions prepared by nanoprecipitation/homogenization based on acid-base neutralization. Int J Pharm. 2012;438(1-2):287-295. doi:10.1016/j.ijpharm.2012.09.020

52. Bootz A, Vogel V, Schubert D, Kreuter J. Comparison of scanning electron microscopy, dynamic light scattering and analytical ultracentrifugation for the sizing of poly(butyl cyanoacrylate) nanoparticles. Eur J Pharm Biopharm. 2004;57(2):369-375. doi:10.1016/S0939-6411(03)00193-0

53. Lindfors L, Skantze P, Skantze U, Rasmusson M, Zackrisson A, Olsson U. Amorphous drug nanosuspensions. 1. Inhibition of Ostwald ripening. Langmuir. 2006;22(3):906-910. doi:10.1021/ la0523661

54. Jacobs C, Kayser O, Muller RH. Nanosuspensions as a new approach for the formulation for the poorly soluble drug tarazepide. Int $J$ Pharm. 2000;196(2):161-164. doi:https://doi.org/10.1016/S03785173(99)00412-3
55. Mauludin R, Müller RH, Keck CM. Kinetic solubility and dissolution velocity of rutin nanocrystals. Eur. J. Pharm. Sci.. 2009;36(4):502510. doi:10.1016/j.ejps.2008.12.002

56. Wang, Y, Li X, Wang L, Xu Y, Cheng X, Wei P. Formulation and pharmacokinetic evaluation of a paclitaxel nanosuspension for intravenous delivery. Int J Nanomedicine. 2011;6:1497-1507. doi:10.2147/IJN. S21097

57. Ganta, S., Paxton JW, Baguley BC, Garg S. Formulation and pharmacokinetic evaluation of an asulacrine nanocrystalline suspension for intravenous delivery. Int $J$ Pharm. 2009;367(1-2):179-186. doi: 10.1016/j.ijpharm.2008.09.022

58. Gao, Y, Li Z, Sun M, et al. Preparation, characterization, pharmacokinetics, and tissue distribution of curcumin nanosuspension with TPGS as stabilizer. Drug Dev Ind Pharm. 2010;36(10):1225-1234. doi:10.3109/03639041003695139

59. Kakkar V, Mishra AK, Chuttani K, Kaur IP. Proof of concept studies to confirm the delivery of curcumin loaded solid lipid nanoparticles (C-SLNs) to brain. Int J Pharm. 2013;448(2):354-359. doi:10.1016/j. ijpharm.2013.03.046

60. Bi, C., Miao XQ, Chow SF, et al. Particle size effect of curcumin nanosuspensions on cytotoxicity, cellular internalization, in vivo pharmacokinetics and biodistribution. Nanomedicine. 2017;13 (3):943-953. doi:10.1016/j.nano.2016.11.004

61. Kulkarni SA, Feng SS. Effects of particle size and surface modification on cellular uptake and biodistribution of polymeric nanoparticles for drug delivery. Pharm Res. 2013;30(10):2512-2522. doi:10.1007/ s11095-012-0958-3

62. Gao K, Jiang X. Influence of particle size on transport of methotrexate across blood brain barrier by polysorbate 80 -coated polybutylcyanoacrylate nanoparticles. Int $J$ Pharm. 2006;310(1-2):213-219. doi:10.1016/j.ijpharm.2005.11.040
International Journal of Nanomedicine

\section{Publish your work in this journal}

The International Journal of Nanomedicine is an international, peerreviewed journal focusing on the application of nanotechnology in diagnostics, therapeutics, and drug delivery systems throughout the biomedical field. This journal is indexed on PubMed Central, MedLine, CAS, SciSearch ${ }^{\mathbb{R}}$, Current Contents ${ }^{\mathbb{B}} /$ Clinical Medicine,

\section{Dovepress}

Journal Citation Reports/Science Edition, EMBase, Scopus and the Elsevier Bibliographic databases. The manuscript management system is completely online and includes a very quick and fair peer-review system, which is all easy to use. Visit http://www.dovepress.com/ testimonials.php to read real quotes from published authors. 